\title{
COVID-19: Current Knowledge and Best Practices for Orthopaedic Surgeons
}

\author{
Abhishek Vaish $^{1} \cdot$ Vijay Kumar Jain $^{2} \cdot$ Karthikeyan P. Iyengar $^{3} \cdot$ Raju Vaishya $^{1}$
}

Received: 20 May 2020 / Accepted: 19 June 2020 / Published online: 2 July 2020

(c) Indian Orthopaedics Association 2020

\section{Dear Editor,}

We congratulate authors for bringing out the most comprehensive review article on COVID-19 and orthopaedic surgeons [1]. Although authors have covered most aspects of this highly contagious disease, there are some best practices that are not included in this article and we would like to highlight these to make it more comprehensive for the readers:

1. The authors have provided the 'Dos' and 'Don'ts' for the orthopaedic surgeons and have rightly emphasized that minimum required members of the surgical team should be present inside the operation theatre. But, who those should be; needs clarification. We believe that the most efficient person in the team to perform a particular orthopaedic surgery should operate on that patient since he would be quick and least traumatic during the surgery. This surgeon may not be the senior-most and the surgeons above 60 years should be kept in reserve [2], as it is known that these individuals are more likely to acquire infection and may not find it comfortable to use PPE for a longer time.

2. We agree that there is a need for surgical risk stratification. There should be a high threshold to offer surgical procedures during this pandemic, and as far as possible the conservative treatment should be preferred. Several fractures were been managed successfully before the era of open reduction and internal fixation became popu-

Abhishek Vaish

drabhishekvaish@gmail.com

1 Department of Orthopedics, Indraprastha Apollo Hospitals, SaritaVihar, Mathura Road, New Delhi 110076, India

2 Department of Orthopedics, Ram Manohar Lohia Hospital, New Delhi, India

3 Department Orthopedics, Southport General Hospital, Omskirk, UK lar in the last four decades, to the extent that almost all fractures are now considered operable. This crisis has perhaps completed the evolution cycle and we have seen a paradigm shift in revisiting conservative management of various orthopaedic problems and fracture management [3].

3. There is no denying that the pandemic has severely disrupted healthcare globally, but optimistically it also has provided us several positives and learning opportunities. We should now understand the importance of optimizing and rationalizing the resources that are available to us. We agree with the authors that the effective use of remote technologies [4] like telemedicine, virtual means of education and knowledge sharing, and utilization of this 'golden time' for research and publication are some of the positives of this pandemic for healthcare providers like ourselves. Research and publications during this pandemic have seen an unprecedented surge [5], globally.

4. Each healthcare facility should have a detailed plan, logistics, and infrastructure for resuming the surgical work [6], and it should not be started in haste.

The authors have interestingly used the reference of 'Ikigai', which is a Japanese secret to a long and happy life. We also believe that balancing clinical practice, academics, and research should bring the best out of us, by way of inner satisfaction and feeling of achievement and this pandemic has allowed us to do so!

Funding None.

\section{Compliance with Ethical Standards}

Conflict of interest The authors declare that they have no conflict of interest. 
Ethical standard statement This article does not contain any studies with human or animal subjects performed by any of the authors.

Informed consent For this type of study an informed consent is not required.

\section{References}

1. Chhabra, H. S., Bagaraia, V., Keny, S., et al. (2020). COVID-19: Current knowledge and best practices for orthopaedic surgeons. Indian Jounal of Orthopaedics. https://doi.org/10.1007/s4346 5-020-00135-1.

2. Jain, V. K., \& Vaishya, R. (2020). COVID-19 and Orthopaedic surgeon: The Indian scenario. Tropical Doctor, 50(2), 108-110. https://doi.org/10.1177/0049475520921616.

3. Iyengar, K. P., Vaish, A., \& Vaishya, R. (2020). Revisiting conservative orthopaedic management of fractures during COVID-19 pandemic. Journal of Clinical Orthopaedics and Trauma. https:// doi.org/10.1016/j.jcot.2020.05.010.
4. Iyengar, K. P., Vaish, A., Toh, E., \& Vaishya, R. (2020). COVID19 and remote consulting strategies in the management of trauma and orthopaedics. Postgraduate Medical Journal. https://doi. org/10.1136/postgradmedj-2020-137917.

5. Iyengar, K. P., Jain, V., Vaish, A., Vaishya, R., Maini, L., \& Lal, H. (2020). Post COVID-19: Planning strategies to resume orthopaedic surgery-challenges and considerations. Journal of Clinical Orthopaedics and Trauma. https://doi.org/10.1016/j. jcot.2020.04.028.

6. Kambhampati, S. B. S., Vaishya, R., \& Vaish, A. (2020). Unprecedented surge in publications related to COVID-19 in the first three months of pandemic. Journal of Clinical Orthopaedics and Trauma. https://doi.org/10.1016/j.jcot.2020.04.030.

Publisher's Note Springer Nature remains neutral with regard to jurisdictional claims in published maps and institutional affiliations. 